\title{
A UNIVERSIDADE POPULAR DOS MOVIMENTOS SOCIAIS: ENTREVISTA COM O PROF. BOAVENTURA DE SOUSA SANTOS*
}

\author{
JÚLIA F. BENZAQUEN
}

$\mathrm{N}$

o desenvolvimento do Fórum Social Mundial (FSM) algumas organizações dos movimentos sociais, ONGs, sindicatos e intelectuais concluíram pela necessidade de dar mais atenção à diversidade dos conhecimentos que circulam na sociedade para fortalecer as lutas sociais, o que Boaventura de Sousa Santos sintetizou na frase "não há justiça social global sem uma justiça cognitiva global". Nesse contexto, começou a ser gerada a ideia de constituição da Universidade Popular dos Movimentos Sociais (UPMS), a qual foi amadurecendo com as seguidas edições do Fórum. Durante o encontro de 2003 do Fórum Social Mundial foi lançada a Universidade Popular dos Movimentos Sociais por uma democracia cognitiva global. ${ }^{1}$

A Universidade Popular dos Movimentos Sociais - Rede Global de Saberes é um espaço de formação intercultural e interpolítica que promove um processo de interconhecimento e autoeducação, com o duplo objetivo de aumentar o conhecimento recíproco entre os movimentos e organizações e tornar possíveis coligações entre eles e ações coletivas conjuntas. Constitui um espaço aberto para o aprofundamento da reflexão, do debate democrático de ideias, da formulação de propostas, da troca livre de experiências e da articulação para ações eficazes, de entidades e movimentos sociais locais, nacionais e globais que se opõem ao neoliberalismo e ao domínio do mundo pelo capital e por qualquer forma de imperialismo.

\footnotetext{
Entrevista inicialmente realizada em Coimbra, no Centro de Estudos Sociais (CES), em 26 de julho de 2011. Posteriormente, em 8 de agosto de 2012, foi complementada e atualizada.

Boaventura de Sousa Santos é professor catedrático jubilado da Faculdade de Economia da Universidade de Coimbra (Portugal), Distinguished Legal Scholar da Faculdade de Direito da Universidade de Wisconsin-Madison (EUA) e Global Legal Scholar da Universidade de Warwick (Reino Unido). É igualmente director do Centro de Estudos Sociais da Universidade de Coimbra; coordenador científico do Observatório Permanente da Justiça Portuguesa e membro do Núcleo Democracia, Cidadania e Direito (Decide).

** Doutora em Sociologia pela Universidade de Coimbra (Portugal). E-mail: juliafb82@yahoo.com.br
} 
Já foram realizadas várias oficinas da UPMS no Brasil e em outros países latino-americanos. São elas: Oficina de Tradução Cultural em Medelín - Colômbia (29 e 30 de setembro de 2007); Oficina na Costa Rica (2007); Oficina de Tradução entre Movimentos Sociais em Córdoba - Argentina (12 e 15 de setembro de 2007); Oficina em Belo Horizonte - Minas Gerais (1 e 2 de agosto de 2009); Oficina em Porto Alegre - Rio Grande do Sul (24 e 25 de julho de 2010).

Durante a reunião da UPMS realizada, no Fórum Social Mundial, em Belém, no ano de 2009 e, posteriormente, na edição do Fórum Social Mundial realizado em Dakar, em 2011, decidiu-se pela realização de três oficinas latino-americanas no Fórum Social Temático (FST), em Porto Alegre (RS), em 2012. Estas aconteceram nos dias 22 e 23 de janeiro de 2012, com os seguintes temas: Oficina 1: Terra e soberania alimentar, direitos humanos,economias solidárias/populares (em São Leopoldo); Oficina 2: Interculturalidade, plurinacionalidade, afrodescendentes, indígenas/dissidência sexual (em Canoas); Oficina 3: Ecologia. Madre Tierra, recursos naturais, extrativismo (em Porto Alegre).

Além dessas oficinas, aconteceram dois encontros da UPMS no FST. O primeiro, no dia 24 de janeiro de 2012, possibilitou o encontro dos integrantes das três oficinas para socialização dos resultados entre os participantes e o segundo, no dia 28 de janeiro de 2012, foi organizado como atividade autogestionária do FST, aberto aos demais interessados com o tema o futuro da UPMS.

É possível afirmar que a realização da atividade autogestionária no FST marcou a refundação da UPMS. Sua organização, a partir de então, ultrapassa a Secretaria Técnica que inicialmente a constituiu, incorporando a participação de outros integrantes, vinculados diretamente aos movimentos sociais, quer sejam ativistas ou intelectuais engajados. Todos eles participantes das três oficinas. Dessa refundação teve origem a constituição de comissões de trabalho para organizar uma nova carta de princípios, parcerias, ampliação internacional da UPMS, atualização e alimentação da home page, construção de grupo de discussão dos integrantes e de orientações gerais para a entrega dos relatórios de cada uma das oficinas realizadas.

No âmbito da Conferência Rio + 20, foi realizada em Aldeia Velha mais uma oficina, nos dias 14 e 15 de junho, com o tema "Saúde, sustentabilidade e bien vivir", bem como outra atividade aberta ao público durante a Cúpula dos Povos, no dia 18 de junho, pela manhã. Esta última intitulou-se UPMS: desafios do futuro e foi uma reunião importante para leitura do texto pré-final da Carta de Princípios da UPMS, documento que deverá conduzir a organização e realização das oficinas nas diferentes regiões do mundo.

O encontro na Cúpula dos Povos foi um importante momento para socializar a trajetória da UPMS até hoje e os resultados dos encaminhamentos acordados durante a atividade autogestionária do FST, em Porto Alegre. 
É possível dizer que a UPMS entrou em um estágio mais maduro. Porém, o que vem a ser a Universidade Popular dos Movimentos Sociais? Quais são os seus objetivos? Para falar sobre isso, ninguém melhor do que o idealizador dessa proposta, o prof. Boaventura de Sousa Santos, do Centro de Estudos Sociais (CES) da Universidade de Coimbra (Portugal).

Júlia Benzaquen (JB): Quais são os objetivos da UPMS? O que é a UPMS? Por que Universidade? Como se propõe a desafiar o conceito de universidade, que tem analisado criticamente nos seus trabalhos? Por que Popular? Por que dos Movimentos Sociais?

Boaventura de Souza Santos (BSS): A primeira pergunta é aquela que está mais caracterizada no meu trabalho. Eu tenho vindo a propor que a universidade é a instituição com mais continuidade, desde a mais distante modernidade ocidental, desde Bolonha. Mas é uma instituição que está neste momento em convulsão bastante grande. E por acaso, curiosamente, o Prêmio Jovens Cientistas Sociais, outorgado pelo CES, em sua edição de 2011, foi ganho por André Rubião - do Observatório da Justiça Brasileira do Centro de Estudos Sociais da América Latina (CES-AL), da UFMG -, pela sua dissertação de doutoramento sobre o tema da universidade participativa, o que é muito interessante.

Tenho vindo a pensar que a universidade nesta fase permite, por um lado, que dentro das universidades convencionais seja necessária muita inovação. E, portanto, tenho vindo a propor, por exemplo, o que designo por extensão ao contrário através da ecologia dos saberes, dentro das universidades convencionais, e tenho vindo a dizer que isso não chega. Isto é, há de haver outras instituições que se reclamam da tradição da universidade, mas que vão fazer aquilo que não é possível fazer dentro de uma universidade convencional. A Universidade Popular dos Movimentos Sociais é uma dessas propostas, entre muitas outras que podíamos imaginar.

Donde é que vem o termo? O termo vem de uma tradição que se desenvolveu, sobretudo, na Europa nas primeiras décadas do século passado, mas também na América Latina, das Universidades Populares que, na altura, estavam muito vinculadas ao movimento operário e aos partidos comunistas. Eram fundamentalmente instituições de caráter de cultura geral para os operários e para as classes populares que não tinham qualquer acesso, digamos, ao ensino formal. Portanto, fui buscar esse termo para propor algo que nasce do mesmo impulso de democratizar o conhecimento, mas que tem desse impulso um entendimento muito diferente. A Universidade é popular, não porque o conhecimento acadêmico tenha de ser divulgado entre as classes populares, mas porque são as classes populares a protagonizar diálogos entre os seus conhecimentos próprios e os conhecimentos acadêmicos.

E dos movimentos sociais por quê? Porque realmente é a forma como as classes populares têm vindo a se organizar, ao contrário do que sucedia no princípio do 
século 20, em que os partidos operários e os sindicatos eram as formas específicas de organização das classes populares, que eram fundamentalmente as operárias; as outras não contavam. Temos hoje formas novas de organização das classes populares e é por isso que se fala em novos movimentos sociais, de formas de organização das classes populares que nem são os partidos e nem são os sindicatos, são os novos movimentos sociais. Portanto, a ideia foi juntar, exatamente: o popular, que evoca uma tradição já conhecida, e os movimentos sociais, que ampliam criticamente essa tradição. Portanto, é popular, mas não é de partidos; é popular, mas é dos movimentos sociais. São instituições de tipo paralelo.

Chamamos de universidade como podíamos chamar de outra coisa; a Escola Florestan Fernandes chamou-se Escola, podia se chamar academia ou outra coisa, mas optamos por nos apropriarmos do termo universidade por pensarmos que é um termo que pode ser apropriado para fins contra-hegemônicos. Se tu quiseres, a UPMS é uma versão contra-hegemônica de um instrumento hegemônico ou de uma instituição hegemônica. Como eu tenho feito para o Direito e para outras áreas, os conceitos, os instrumentos, as instituições hegemônicas podem ser usados para objetivos e para formas contra-hegemônicas ou para fins contra-hegemônicos. A UPMS é exatamente isso, uma maneira de utilizar a universidade de forma contra-hegemônica.

O objetivo geral da UPMS é contribuir para que o conhecimento da globalização alternativa seja tão global quanto ela e que, nesse processo, as ações transformadoras sejam mais esclarecidas e eficazes e os seus protagonistas, mais competentes e reflexivos. Para atingir este objetivo, a UPMS terá de ser mais internacional e mais intercultural do que as iniciativas existentes que com ela têm alguma semelhança.

JB: O que a UPMS tem de comum com outras experiências de educação popular? O que a UPMS tem de específico? Em que sentido a tradução intercultural difere da proposta de Paulo Freire?

BSS: Obviamente que, sobretudo na América Latina, mas também em África, há uma riquíssima tradição de educação popular. Quem participa na Universidade Popular dos Movimentos Sociais são líderes ou ativistas dos movimentos sociais que já têm um conhecimento e uma experiência social e política que se vinculam e articulam na UPMS. Então, a UPMS é uma troca de saberes, é uma ecologia de saberes basicamente.

Paulo Freire, de alguma maneira, organiza todo o seu modelo de educação popular dentro de uma grande preocupação com as divisões sociais, de classes e de desigualdades de classes, com os oprimidos, mas com pouca ênfase na diversidade cultural. Esse recorte de Paulo Freire na questão das classes possui boas razões. Porém, os movimentos sociais vieram trazer ao nosso conhecimento o fato de que não há apenas divisões de classes, há também as divisões culturais e modos desiguais de 
se tratar as culturas. Divisões, desigualdades e formas de discriminação contra índios, negros, quilombolas, mulheres, povos do campo, população GLBT, etc. Aprendemos com os movimentos sociais que as relações de poder são mais complexas. Além disso, mais do que uma vocação que tenha como escala as localidades, as regiões e o país, como é mais enfatizado por Paulo Freire (sem desconsiderar a influência de seus estudos e práticas no contexto internacional), a UPMS tem uma vocação mais internacional que não se realizou até agora em pleno, mas já teve o seu início em janeiro deste ano, no Fórum Social Temático, em Porto Alegre. Essa vocação é internacional e intercultural. Portanto, congrega uma diversidade não só de atores, mas, sobretudo, diversidades culturais. A UPMS se guia pela tradução intercultural.

Não há na UPMS uma doutrina, um princípio dogmático que seja orientado a partir de um comitê central que diga qual é a linha correta, quais são os movimentos que estão certos, quais são as formas de saber que estão certos. A única hipótese é a tradução intercultural que é a alternativa à teoria geral. É a forma pela qual, por vezes, nós podemos traduzir isso. Obviamente, a tradução intercultural pode ter lugar entre universos simbólicos totalmente distintos ou muito distintos. E universos simbólicos que tenham variações internas. Então, entre o urbano e o rural há uma diferença, mas não é tão grande quanto a diferença entre o urbano e o rural, no seu conjunto, e o indígena ou o afro, por outro lado. Portanto, há graus diferentes de diversidade cultural. A UPMS, efetivamente, procura captar através da tradução intercultural maneiras de podermos criar inteligibilidade, pautada no respeito às autonomias e às diferenças, etc. Ao fazê-lo, cuida para que essas diferenças não se tornem nem incomensuráveis ou incomunicáveis, nem que se caia no relativismo. É importante que haja espaço para o diálogo, para a conversa por meio da hermenêutica diatópica, como já expliquei nos meus livros sobre teoria social. Basicamente, a tradução intercultural é em função disto.

JB: Segundo o texto sobre a UPMS, da Gramática do tempo (Santos, 2006, p. 171): "A UPMS é composta por três atividades principais: atividades pedagógicas, atividades de pesquisa-ação para a transformação social e atividades de difusão de competências e instrumentos de tradução intertemática, transnacional e intercultural". As atividades de pesquisa-ação aconteceriam no sentido de criar e não apenas articular os saberes plurais para a transformação. Foram desenvolvidas atividades de pesquisa-ação no âmbito da UPMS? Se foram desenvolvidas, de que maneira? Se não aconteceram, por quê?

BSS: O projeto da UPMS tem realmente na sua matriz a ideia de que pudéssemos ir além dessas atividades de formação, o que nós chamamos de oficinas, mas poderíamos chamar de formação coletiva, autoformação, autoaprendizagem; que nós pudéssemos ter também formas de pesquisa-ação mais avançada, isto é, eu continuo a pensar que, ainda hoje, é muito difícil realizar, ao nível das universidades ou dos centros de investigação, pesquisa que corresponda efetivamente à necessidade dos 
diferentes atores sociais, porque é inclusivamente difícil captar quais são as suas necessidades, porque eles não são audíveis, não estão nas universidades e, obviamente, não podem estar nos concursos da Capes... Portanto, a UPMS tem essa vocação de, eventualmente ou no futuro, ser um centro a partir do qual surgem iniciativas por parte dos movimentos que é preciso investigar, fazer pesquisa e que essa pesquisa possa ser feita pela UPMS. Até agora isso não foi possível. Por que não foi possível? Bem, não foi possível porque não tem sido fácil financiar a UPMS. Ela não é um projeto comum que se aproxima dos formatos das ONGs internacionais que apoiam o desenvolvimento internacional no chamado terceiro mundo. Não entra nisso porque é muito politizada na forma de criar entendimento entre os movimentos sociais para a transformação social. Por outro lado, também não é um projeto de investigação, não é um projeto de pesquisa. Portanto, não é nem uma coisa nem outra, e isso foi o que tornou impossível até agora que a UPMS se desenvolvesse mais. Basicamente, foi essa a razão.

JB: De acordo com o mesmo texto, as atividades de difusão de competências e instrumentos de tradução organizariam os resultados dos momentos pedagógicos e das pesquisas, naquilo que o professor chamou de léxicos e de manifestos. Até onde tenho conhecimento, não foram organizados nem léxicos e nem manifestos. No entanto, os relatórios das oficinas realizadas passaram a ter uma função central. Qual o sentido desses relatórios? Existe alguma forma específica para produzi-los? O objetivo dos relatórios é serem o mais fiel possível com a realidade ou servirem de inspiração para outras oficinas?

BSS: É preciso ver que o que foi publicado na Gramática do tempo é realmente o programa amplo da UPMS. Eu resolvi aí estabelecer o horizonte de possibilidades da UPMS para tentar ver que o horizonte é muito vasto e a realização é que pode ficar aquém. Basicamente é isso. Portanto, por um lado, tinha ali a questão da pesquisa-ação e, por outro lado, tinha a ideia de que, dessa forma de autoaprendizagem coletiva muito intensificada, iriam começar a surgir novas noções de esquerda, novas noções de política, novas noções de emancipação social, novos conceitos como, por exemplo, aqueles que foram surgindo, trazidos pelo próprio movimento indígena: os conceitos de Sumak kawsay e de Pachamama presentes nas universidades indígenas. Portanto, houve uma série de novidades que foram trazidas para a educação. A nossa ideia é que a Universidade Popular pode estar nessa origem, porque está, digamos assim, a receber de maneira primária, direta, através das oficinas, o conhecimento que circula entre os movimentos sociais e que estes possam a partir daí começar a desenvolver novos conceitos. É esta a noção dos novos léxicos. Por outro lado, essas ideias e esses conceitos podem nos levar a estabelecer novas cartas de princípio, digamos, novos manifestos. São princípios de ação, convites, chamadas para ação, novas formas de ação, novos objetivos, novos slogans, novas estratégias para a transformação social. Bem, é evidente que isto 
não foi avante porque até agora, como eu digo, a UPMS ainda não se tornou numa prioridade para os movimentos e também porque não foi possível que alguém se pudesse ocupar o tempo inteiro da UPMS. Todo o trabalho tem sido voluntário. Também não consegui que nenhuma das ONGs mais diretamente envolvidas, nem sequer do meu Centro, a assumisse, porque no meu Centro teria que ser através de um projeto de investigação e, como disse, essa parte ficou precludida. Da parte das ONGs, cada uma das que participam tem a sua própria agenda, as suas próprias formas de educação popular e, apesar de terem apoiado a UPMS, não transferiram recursos, sobretudo humanos, que podiam, eventualmente, ter transferido para podermos ter um pequeno grupo internacional que pudesse trabalhar mais intensamente nisto.

É evidente que, no momento em que entrarmos em léxicos e manifestos, a Universidade Popular será mais polêmica, talvez nos léxicos nem tanto, mas, sim, nos manifestos, pois teremos que tomar posição. Ao longo destes anos, a UPMS tem sido uma experiência que atraiu muita gente, muita gente curiosa. A sua própria tese e a da Ana Prestes são exemplos disso, assim como outras que estão em preparação. Isso porque a UPMS é uma ideia que captou a imaginação das pessoas e que se insere, então, num conjunto de outras universidades que já existem.

A minha ideia inicial era que a UPMS pudesse, mais tarde ou mais cedo, ser adotada pelo Fórum Social Mundial (FSM), como, digamos assim, uma das suas dimensões. Ela hoje funciona junto ao Fórum, com gente dele, mas não é uma instituição do Fórum, não foi discutida pelo Conselho Internacional, por exemplo. Mas eu pensei numa maior vinculação ao FSM, sobretudo no momento em que, por volta de 2004, 2005, houve certa crise do processo do FSM, que depois foi ultrapassada. Pensava que, eventualmente, se houvesse uma crise no Fórum que pusesse em causa a sua realização, a Universidade Popular poderia assegurar certa continuidade da reflexão, porque o espírito do FSM está todo na UPMS: é o espírito não dogmático das articulações entre diferentes movimentos; é mais horizontal do que vertical, embora naturalmente tenha que ter algum princípio de organização e, eu tenho que dizer, o Fórum não foi ainda apropriado pelos movimentos sociais, é um processo ainda em curso. Também não foi apropriado por ONGs, o que é curioso. Ele não foi suficientemente forte para que também algumas ONGs decidissem apropriá-lo, chamá-lo de seu e controlá-lo. De fato, tem sido sempre a minha política tentar que haja espaços de grande criatividade, através de um princípio que tem sido seguido de alguma maneira e que me parece ser o mais correto: é haver algumas ideias gerais que, entretanto, se foram construindo sobre a UPMS, não carregar muito sobre metodologias e princípios e deixar que aqueles que organizam as oficinas sejam as pessoas mais legítimas para falar em nome da própria UPMS. E, portanto, continuo a pensar que as pessoas que podem falar 
sobre a UPMS, sobre a sua prática, entre outros aspectos, são aquelas pessoas que organizaram as oficinas. Não é nenhuma teoria que eu tenha produzido; produzi a ideia, avancei a ideia e acompanho sempre com muito carinho. As pessoas continuam a querer a minha participação nas oficinas da UPMS que vão sendo realizadas, mas é evidente que a atividade da UPMS decorre de quem a organiza, são eles que conhecem os problemas: a Norma Fernandez, em Córdoba, a Nilma Gomes, em Belo Horizonte, sobretudo, e a Beatriz Soto, em Medellin, são pessoas com quem tive muitas conversas, antes, durante e logo depois das oficinas, que mostraram como elas tinham suscitado problemas novos, porque estes surgiram quando elas estavam a organizar as oficinas e é com base nisso que eu tenho vindo a alimentar a minha própria elaboração. Portanto, eu acho que é cedo demais para isso, para os manifestos.

As oficinas realizadas produzem, ao final, os relatórios. Tenho chamado esse produto de relatório, pois não quero chamar de sistematização porque há toda uma filosofia, uma metodologia de sistematização da educação popular e há organizações especializadas em sistematização. E eu, francamente, sou sempre um bocado contra todos os códigos e uniformizações, porque eu penso que a UPMS é uma entidade ainda muito frágil de formação. E, portanto, eu não queria que os relatórios também tivessem formatos. Quero que aqueles que organizam as oficinas definam os seus próprios modelos de relatório e tragam coisas diferentes. Se tu olhares para os relatórios das diferentes oficinas, verás que são muito diferentes, em estilo, em preocupação e até em forma, nos aspectos formais do próprio relato.

JB: A ideia de propagação da UPMS é que, a partir da realização de uma oficina, outras irão surgindo de acordo com os interesses dos movimentos sociais participantes, e a proposta vai se ampliando. Quais as instituições elou pessoas possuem legitimidade para propor e promover oficinas da UPMS? Cada movimento social que se identifica com a Carta de Princípios da UPMS deve ser capaz de ter a iniciativa de organizar oficinas ou outras atividades? Mas existe o risco de que a proposta seja desvirtuada por alguém que não a entenda bem ou que tenha interesses escusos. Como fazer esse controle e ao mesmo tempo estimular a expansão da proposta?

BSS: A questão da legitimidade da UPMS é fundamental porque realmente nós não temos nenhuma certificação de legitimidade para fazer as oficinas. $\mathrm{O}$ que nós temos tido é na base da confiança das pessoas que estiveram próximas na formação da UPMS, que estiveram nos atos fundadores dentro do Fórum Social Mundial, nos painéis que realizamos, nas oficinas, enfim, que estiveram aí presentes. As pessoas que foram se identificando com a UPMS são aquelas que têm vindo a fazer propostas. Mas já tivemos propostas de organizações que até fazem consultoria de formação e que acharam que a ideia da UPMS era interessante e quiseram fazer sessões da UPMS com seminários pagos, o que causou certo embaraço, porque nós não temos nenhuma agência de legitimação ou certificação. 
Após a refundação da UPMS no Fórum Social Mundial, em Porto Alegre, com a realização das três oficinas internacionais, fizemos uma assembleia no dia 28 de janeiro e construímos orientações e procedimentos para a continuidade da UPMS com comissões internacionais. Será construída uma nova carta de princípios, a partir daquela que já existe e com contribuições dos participantes das três oficinas. Também teremos princípios e orientações para a construção de parcerias, para a reativação do nosso site, entre outras coisas. Qualquer movimento que participa no Fórum Social Mundial pode organizar oficinas da UPMS. Não estamos livres de que alguém queira organizar alguma coisa e que a gente possa dizer que temos copyright sobre isto e sobre as formas de organização. É como na educação popular: quantas coisas se dizem que é educação, cidadão, educação popular e não são. Obtiveram o nome e utilizaram o nome. Por acaso, o nosso nome é demasiado específico para as pessoas tentarem dele se apropriar. A UPMS é um bocado mais difícil de imitar, as pessoas não entendem muito bem essa mistura entre intelectuais ou universitários ou não, artistas, comprometidos com os movimentos sociais e líderes ou ativistas dos movimentos. É uma proposta mais difícil. Isso é um núcleo duro, em meu entender, da organização da UPMS.

Obviamente, há o risco de que a proposta seja desvirtuada. Está aí. Até agora, por que não corremos muito esse risco? Porque a Universidade Popular não se desenvolveu muito; por enquanto, ela ainda é pouco conhecida. Há muito mais gente que conhece o slogan da UPMS, que tem curiosidade por ela, mas não sabe muito bem o que ela é, como funciona e nunca teve ocasião para nenhum contato direto. Nós também não tivemos nenhum staff, nenhum pessoal e nem mesmo material que possa ser distribuído para além do que está no nosso site.

JB: Com relação à viabilidade, é importante pensar a respeito do financiamento das atividades da UPMS. Quem pode conseguir recursos pela UPMS? É interessante institucionalizá-la em uma pessoa jurídica, no sentido de permitir pedido de financiamento? Quais as desvantagens da institucionalização?

BSS: É uma boa questão. Discutimos, durante o FST, com o governo de Porto Alegre a possibilidade de abrigar uma sede da UPMS no Memorial do Fórum Social Mundial e nossa proposta foi aceita. Mas isso não quer dizer que o trabalho da UPMS se limite ao Brasil. Quer dizer, não quero que ela seja brasileira ou argentina ou colombiana. O meu grande objetivo é internacionalizar a UPMS. Na assembleia da UPMS durante o FST e no encontro realizado no Rio de Janeiro, durante a Cúpula dos Povos, discutimos que um dos eixos da organização da UPMS serão as parcerias com governos progressistas e universidades ou núcleos de pesquisa que atuem de forma articulada com os movimentos sociais. Mas essa parceria tem que ser mais bem discutida para não incorrer em aparelhamento ou aprisionamento da UPMS. Ela tem que continuar autônoma. 
JB: As atividades até agora realizadas pela UPMS se centraram na América Latina. Por quê? Outras oficinas elou atividades estão a ser planejadas noutros contextos geográficos?

BSS: Centra-se na América Latina por uma razão simples: é uma experiência internacional e não obriga à tradução simultânea. Porque nós não temos dinheiro para tradução simultânea e acho que, entre espanhol e português, com o "portunhol", a gente entende-se. Para termos movimentos da África ou da Ásia, teríamos que conduzir tudo em inglês ou então com tradução simultânea e, para isso, é preciso muito dinheiro. A razão é um pouco esta. Mas também foi retirada na assembleia do FST uma comissão internacional que irá articular oficinas da UPMS na Europa e na África. Estamos a crescer.

JB: Como avalia as atividades até então desenvolvidas pela UPMS? Qual o potencial da UPMS? Como vê o desenvolvimento da UPMS?

BSS: Tenho um grande carinho por esta iniciativa. Considero certa paternidade nisso. Por quê? Por que acho isso muito importante? Porque, realmente, no fundo, isso foi a minha maneira de dar alguma institucionalidade à minha epistemologia, quer dizer, todo o meu trabalho de epistemologia. As epistemologias do Sul operam através desses dois grandes procedimentos: a ecologia dos saberes e a tradução intercultural. Ora são estes exatamente os mesmos instrumentos que orientam a UPMS. De alguma maneira, a UPMS significa as epistemologias do Sul aplicadas. O meu sonho, digamos assim, o meu objetivo é este: uma forma de aplicar as epistemologias do Sul. Eu ando, por um lado, a fazer conferências por todo o mundo sobre isso e a escrever livros e, por outro lado, está em gestação uma instituição que procura desenvolver, na prática, as epistemologias do Sul. Também por isso é importante que não haja nenhum engessamento da UPMS. Eu tenho vindo a aplicar as epistemologias do Sul à própria ideia da UPMS. E se ela é, de fato, uma expressão das epistemologias do Sul, ela tem que ser construída também sob uma lógica destas epistemologias, que é nunca perder de vista as necessidades, as aspirações e os conhecimentos daqueles que nela participam e respeitar muito isso. Pois quanto mais tivermos uma visão cerrada, mais difícil é incluir a diversidade. Tem uma metodologia, que são princípios muito gerais e depois a gente chega a uma oficina e deixa a liberdade criativa seguir, porque pode haver gente que diga: - mas eu gostava que fosse dessa maneira ou desta. Não há nenhum impedimento para que isso ocorra dentro do projeto da UPMS. Ao contrário, se nós tivéssemos uma metodologia cerrada, teríamos depois aqueles indivíduos que se considerariam, digamos, os pais da metodologia. Poderíamos repetir alguma coisa que acabou por suceder com a experiência de Paulo Freire, com um grupo que se considera os únicos herdeiros do legado de Paulo Freire. Eu penso que ser freireano ou ser da UPMS é estar em consonância com os objetivos de hoje e, portanto, não podemos ter nenhum dogmatismo, nenhum catecismo. As coisas tiveram a origem que tiveram, com as pessoas que 
estiveram envolvidas. O que nós partilhamos todos é, isso sim, a proposta das epistemologias do Sul, a nossa resposta a um problema político em que convergimos. Qual é o problema político? É articular as diferentes ações dos diferentes movimentos sociais sem destruir a autonomia deles. Para isso, é preciso criar inteligibilidades múltiplas e interconhecimento. A Universidade Popular dos Movimentos Sociais é um esforço de interconhecimento. E é isto.

\section{Nota}

1. Disponível em: <http:// www.universidadepopular.org>

\section{Referência}

SANTOS, B.S. A gramática do tempo: para uma nova cultura política. São Paulo: Cortez, 2006. 